\title{
ENSAIO IMUNOENZIMÁTICO COMERCIAL NO DIAGNÓSTICO SOROLÓGICO DAS INFECÇÕES POR HERPESVÍRUS BOVINO $1^{(1)}$
}

\author{
A COMMERCIAL ENZYME IMMUNE ASSAY IN SERODIAGNOSIS \\ OF BOVINE HERPESVIRUS 1 INFECTIONS
}

\author{
Kerlei Cristina Médici ${ }^{2}$ Amauri Alcindo Alfieri ${ }^{3}$ Alice Fernandes Alfieri ${ }^{3}$
}

- NOTA -

RESUMO

Avaliou-se o desempenho de um ensaio imunoenzimático, obtido de fonte comercial, na identificação de anticorpos contra herpesvírus bovino tipo 1 (BHV-1), induzidos tanto por infecção natural quanto por vacinação, em 1000 amostras de soros sangüineos de bovinos. A análise comparativa dos resultados obtidos no sistema avaliado e na técnica padrão de soroneutralização mostrou uma concordância de 97,05\% $(K=0,94)$ entre as duas metodologias de diagnóstico sorológico.

Palavras-chave: herpesvirus bovino tipol, sorologia, soroneutralização, ensaio imunoenzimático.

\section{SUMMARY}

The performance of a commercial immune assay in the identification antibody of natural infection or vaccination against bovine herpesvirus type 1 (BHV-1) in 1000 samples of bovine serum was evaluated. The comparative analysis from the result of the evaluated system and standard serum neutralization technique showed a rate of agreement of $97.05 \% \quad(K=0.94)$ between the two serologic diagnotic methods.

Key words: bovine herpesvirus type 1, serology, serum neutralization, enzyme immune assay.

As infecções por herpesvírus bovino tipo 1 (BHV-1), dentro do complexo rinotraqueíte infecciosa bovina (IBR) e vulvovaginite / balanopostite pustular infecciosa (IPV/IPB) podem determinar diferentes sinais clínicos na espécie bovina e apresentam como consequiência grandes prejuízos econômicos às pecuárias de corte e leite (KAHRS, 1977). Na dependência do subtipo viral envolvido, particularmente, nas primo-infecções, essa virose pode manifestar-se de forma respiratória, ocular, septicêmica e/ou reprodutiva (BHV-1.1 -IBR-like); genital (BHV-1.2 $\mathrm{A}$, BHV-1.2 $2_{\mathrm{B}}$-IPV/IPB-like-) e nervosa (BHV-5) (PAULI et al., 1981; SCHUDEL et al., 1986; ROIZMANN et al., 1992 e 1995; MAGYAR et al., 1993). Essa gama de formas de apresentação clínica, também compatíveis com infecções causadas por outros microrganismos, praticamente inviabiliza o diagnóstico clínico dessa virose.

O diagnóstico etiológico definitivo da infecção pode ser realizado com o isolamento viral ou a detecção de antígenos e/ou genoma de BHV-1 em material biológico. Entretanto, essas metodologias apresentam fatores limitantes, tais como colheita, conservação e transporte da amostra e mesmo a disponibilidade de laboratórios de diagnóstico que realizem essas técnicas rotineiramente (CANANT, 1984). Como alternativa, freqüentemente, utiliza-se a sorologia (PRITCHARD, 1985). Essa metodologia

\footnotetext{
${ }^{1}$ Apoio financeiro: CNPq, CPG/UEL.

${ }^{2}$ Médico Veterinário, aluna do Programa de Mestrado em Sanidade Animal.

${ }^{3}$ Professores do Departamento de Medicina Veterinária Preventiva (Laboratório de Virologia Animal) / CCA / Universidade Estadual de Londrina, 86051-990, Londrina/Pr. E-mail: alfieri@npd.uel.br 
fornece importantes informações epidemiológicas sobre a presença e/ou ausência da infecção nos plantéis estudados, bem como, possibilita a quantificação da frequiência de animais sororreagentes dentro de um rebanho e/ou região. A maioria dos laboratórios de diagnóstico utilizam nos levantamentos soroepidemiológicos a técnica de soroneutralização (SN). Essa metodologia, por apresentar grande especificidade e mesmo sensibilidade é considerada a técnica de referência para o diagnóstico sorológico das infecções por BHV-1. Entretanto, a SN apresenta alguns inconvenientes na sua realização, pois depende de cultivo celular (WYLER et al., 1990).

Com o objetivo de facilitar a realização de levantamentos epidemiológicos, uma série de métodos sorológicos alternativos foram desenvolvidos (COLLINS et al., 1984). Porém, devido a sua maior sensibilidade, padronização de reagentes, facilidade de execução e por permitir a análise de amostragens significativamente maiores, em intervalos menores de tempo, os ensaios imunoenzimáticos (ELISA) destacam-se como ferramenta indispensável em levantamentos epidemiológicos e mesmo no diagnóstico sorológico das infecções por BHV-1 (KRAMPS et al., 1994; PERRIM et al., 1996).

Este trabalho teve como objetivos a avaliação do desempenho de um sistema de ELISA comercial, na detecção de anticorpos antiBHV-1, e a comparação dos resultados obtidos com a técnica de SN. Foram utilizadas 1000 amostras de soros sangüíneos, colhidas no período de junho de 1995 a junho de 1996 em rebanhos bovinos de corte e leite de vários municípios do Estado do Paraná, Brasil, estocados até o processamento a $-18^{\circ} \mathrm{C}$. Na amostragem, foram incluídas 68 amostras de soros provenientes de um rebanho de bovinos leiteiros livre de IBR. Também fizeram parte da amostragem 158 soros de animais adultos, de três rebanhos leiteiros, colhidos entre 30 a 45 dias após a segunda dose da vacinação contra IBR. Em todos os testes, foram incluídos soros controles, previamente identificados como negativos e/ou positivos para o BHV-1, utilizados na rotina sorológica do laboratório. No total, foram empregados 10 soros controles representados por: i) controle negativo: cinco amostras de soros de bezerros, provenientes de propriedade livre de IBR; ii) controle positivo: cinco amostras de soros de bezerros, inoculados experimentalmente com o protótipo Los Angeles (LA) de BHV-1 para produção de soro hiperimune.

A microtécnica de $\mathrm{SN}$ foi realizada com células MDBK (Madin Darby bovine kidney) e 100 TCID 50\% (REED \& MUENCH, 1938) do protótipo viral LA de BHV-1, com incubação vírus/soro por uma hora, a $37^{\circ} \mathrm{C}$, em atmosfera de $5 \%$ de $\mathrm{CO}_{2}$, segundo metodologia descrita por BRITSCH (1978). Para a manutenção das células MDBK foi utilizado o meio de cultura Dulbecco's Modified Eagle's Medium $^{1}$.

Para a detecção de anticorpos séricos contra o BHV-1 por ELISA, foi empregado um sistema comercial $\left(\right.$ HerdChek $^{\circledR 2}$ ). Todos os procedimentos para a realização da técnica foram conduzidos de acordo com o manual técnico e protocolo idealizados pelo fabricante. A densidade óptica (DO) de cada amostra, correspondente à absorbância em comprimento de onda entre 620 e $650 \mathrm{~nm}$, foi obtida em espectrofotômetro de leitura automática $\left(\operatorname{Emax}^{\mathrm{TM}^{3}}\right)$. Para a interpretação dos resultados, utilizou-se um software que, após a validação do sistema, classifica cada amostra como positiva, negativa ou suspeita (HerdChek $\left.{ }^{\circledR 2}\right)$.

Todos os soros, testados na diluição de $1: 25$, foram inicialmente avaliados pelo sistema de triagem disponível no kit. As amostras consideradas suspeitas na triagem, e também aquelas em que não se obteve coincidência de resultados entre a SN e o ELISA, foram submetidas ao sistema de verificação do kit. Esse sistema, utilizado para identificação de reações inespecíficas como as induzidas por anticorpos contra antígenos celulares, constitui-se basicamente no reteste pareado das amostras e comparação das DO obtidas nas cavidades adsorvidas com antígenos de BHV-1 com as de antígenos celulares. Também nessa situação, a interpretação dos resultados foi conduzida com a utilização do software fornecido pelo fabricante.

O grau de concordância entre as duas metodologias de diagnóstico sorológico foi analisado através do sistema SAS (Statistic Analysis System), utilizando o índice Kappa (GART \& BUCK, 1966).

A tabela 1 apresenta a distribuição dos resultados obtidos na análise comparativa de 983 soros bovinos através das técnicas de SN e ELISA, nas quais evidencia-se um índice de 97,05\% de concordância entre as metodologias avaliadas no diagnóstico sorológico das infecções por BHV-1. Tomandose como referência a técnica de $\mathrm{SN}$, a análise dos resultados obtidos na técnica de ELISA revelou uma sensibilidade de $100 \%$ e especificidade de $94,88 \%$.

Devido ao efeito tóxico observado nos controles de soro na técnica de SN, não foi possível a realização da análise comparativa dos resultados em $17(1,7 \%)$ amostras. Dessas, seis amostras foram positivas e onze negativas no sistema de triagem do teste de ELISA. Apesar de serem tóxicas em cultivo celular não foi necessário, em nenhuma das 17 amostras, a utilização do sistema de verificação do teste de ELISA uma vez que as densidades ópticas, 
Tabela 1 - Distribuição dos resultados da sorologia para herpesvírus bovino tipo 1, obtidos através das técnicas de Soroneutralização e Ensaio Imunoenzimático (ELISA) comercial. ${ }^{(\#)}$

\begin{tabular}{lccc} 
ELISA $\left(\right.$ HerdChek $\left.^{\circledR}\right)$ & \multicolumn{2}{c}{ SORONEUTRALIZAÇÃO } & TOTAL \\
\cline { 2 - 3 } & REAGENTES & NÃO REAGENTES & \\
& & & \\
& & 29 & 445 \\
REAGENTES & 416 & 538 & 538 \\
NÃO REAGENTES & 0 & 567 & 983 \\
TOTAL & 416 & & \\
& & &
\end{tabular}

(\#) Índice Kappa: $K=0,94$.

tanto das amostras positivas quanto das negativas, apresentaram valores fora da faixa de dúvidas do sistema.

Nos procedimentos de tabulação geral dos dados, foram identificadas $9(0,9 \%)$ amostras nas quais os resultados inicialmente não apresentaram concordância com os obtidos na maioria das outras amostras analisadas. Sete amostras reagentes por SN em diluições $\geq 1: 16$ foram negativas no sistema de triagem da técnica de ELISA. Ao reteste, as sete amostras foram positivas, tanto no sistema de triagem quanto no de verificação, com DO entre 0,635 e 1,068. Conclui-se que houve uma falha técnica, como erro de pipetagem ou falha na homogeneização da amostra durante a realização do primeiro teste de ELISA. Outras duas amostras, consideradas não reagentes à $\mathrm{SN}$, apresentaram $\mathrm{DO}$ de $0,737 \mathrm{e}$ 0,815. Ao reteste do ELISA, também realizado nos sistemas de triagem e de verificação, ambas as amostras apresentaram DO $<0,150$. Uma provável explicação para o primeiro resultado do ELISA é a possibilidade de ter havido contaminação dos orifícios da placa durante as etapas de lavagem, considerando que todas as etapas desse procedimento foram realizadas manualmente e não em sistemas automatizados que evitam esse problema.

A coincidência de resultados, negativos e positivos, observada em 97,05\% (954/983) das amostras analisadas demonstra a alta especificidade do sistema de ELISA avaliado. O índice Kappa mostrou que houve uma concordância quase perfeita $(\mathrm{K}=0,94)$ entre os resultados apresentados pelos dois testes, tendo $95 \%$ de confiabilidade.

Todos os controles, negativos (5 amostras) e positivos (5 amostras), apresentaram os resultados esperados em ambos os sistemas de diagnóstico utilizados. Ainda com relação às amostras incluídas na avalição como controles, nenhum dos 68 soros bovinos provenientes de propriedade livre de IBR reagiu no procedimento de triagem da técni- ca de ELISA, caracterizando a não ocorrência de resultados falso-positivo na amostragem estudada.

Das 158 amostras de soros colhidas de animais recentemente vacinados contra BHV-1, as duas técnicas apresentaram resultados semelhantes em 150 (94,9\%) amostras. Dessas, 145 $(91,77 \%)$ foram sororeagentes e $5(3,16 \%)$ não reagentes. Porém, $8(5,06 \%)$ amostras foram consideradas SN negativas / ELISA positivas, mesmo após a realização do sistema de verificação. Por ser tratar de amostras provenientes de animais vacinados, esse resultado sugere que a técnica de ELISA avaliada é sensível o suficiente para detectar anticorpos vacinais, mesmo em títulos basais, uma vez que, todas as oito amostras, apesar de terem sido interpretadas como negativas em $\mathrm{SN}$, foram reagentes na diluição de 1:2.

A observação de que $100 \%$ das amostras reagentes em SN também foram positivas em ELISA, caracteriza a não ocorrência de resultados falso-negativo no sistema avaliado. Resultados divergentes entre as metodologias de diagnóstico utilizadas neste estudo foram encontrados em 2,95\% das 983 amostras analisadas. Vinte e nove soros, negativos por SN, foram considerados positivos pelo sistema de triagem do ELISA. Esses resultados foram ratificados após a reanálise destes soros, tanto por SN quanto pelo sistema de verificação da técnica de ELISA.

Deve-se ressaltar ainda que, 11 (37,9\%) das 29 amostras com resultados conflitantes foram sororreagentes na técnica de SN na diluição de 1:2. Porém, em uma análise global, esses soros foram considerados negativos, uma vez que, devido à padronização da técnica de $\mathrm{SN}$, somente são considerados positivos os soros que inibem $100 \%$ do efeito citopático nas diluições $\geq 1: 4$. Outras $8(27,6 \%)$ amostras, que não apresentaram coincidência de resultados entre as técnicas avaliadas, referem-se a soros colhidos de animais vacinados, já discutidos anteriormente.

Outro aspecto que deve ser analisado é que as 29 amostras ELISA positivas/ SN negativas eram provenientes de 16 diferentes propriedades rurais onde o índice médio de soroconversão para BHV-1 era superior a $47 \%$, evidenciando a grande difusão dessa virose nesses plantéis.

Considerando: i) a facilidade e rapidez de execução; ii) a possibilidade de automação dos dados e resultados, com o uso de um software específico; iii) a viabilidade de padronização de resultados entre laboratórios de diagnóstico; iv) e principalmente, os resultados obtidos neste estudo comparativo, o ensaio imunoenzimático avaliado apresenta-se 
como uma alternativa viável para a realização de diagnóstico sorológico e levantamentos epidemiológicos das infecções por BHV-1, bem como, para monitoramento de plantéis livres da infecção e análises do perfil sorológico pós-vacinal (IBR) em rebanhos bovinos.

\section{FONTES DE AQUISIÇÃO}

${ }^{1}$ Sigma Chemical, Co., St. Louis, MO, EUA.

${ }^{2}$ HerdChek ${ }^{\circledR}$ : Anti-IBR; Bovine Rhinotracheitis Virus Antibody Test Kit Screening / Verification, IDEXX Laboratories, Inc. Westbrook, Maine, EUA.

${ }^{3} \mathrm{Emax}^{\mathrm{TM}}$, Molecular Devices Corporation, Ca, EUA.

\section{REFERÊNCIAS BIBLIOGRÁFICAS}

BRITSCH, V. The modification of the infectious bovine rhinotracheitis virus serum neutralization test. Acta Veterinaria Scandinava, v.19, p.497-505, 1978.

CANANT, J.C. Diagnosis of the cause bovine abortion, part 1 . Modern Veterinary Pratice, v.1, p.929-931, 1984.

COLLINS, J.K., BULLA, G.A., RIEGEL, C.A., et al. A single dilution enzyme-linked immunosorbent assay for the quantitative detection of antibodies to bovine herpesvirus type 1. Veterinary Microbiology, v.10, p.133-147, 1984.

GART, J.J., BUCK, A.A. Comparison of a screning test and a reference test in a epidemiologic studies. American Journal of Epidemiology, v.83, n.1, p.593-602, 1966.

KAHRS, R.F. Infectious bovine rhinotracheitis: A review and update. Journal Veterinary Medicine Association, v 171 n.10, p.1055-1064, 1977.

KRAMPS, J.A., MAGDALENA, J., QUAK, J., et al. A simple specific and highly sensitive blocking enzyme-linked immunosorbent assay for detection of antibodies to bovine herpesvirus 1. Journal of Clinical Microbiology, v.32, n.9, p.2175-2181, 1994.

MAGYAR, G., TANYI, J., HORNYÁK, A., et al. Restriction endonuclease analysis of Hungarian bovine herpesvirus isolates from different clinical forms of IBR/IPV and encephalitis. Acta Veterinaria Hungarica, v.4, n.1-2, p.159$170,1993$.

PAULI, B., DAROI, G., STORZ, J., et al. IBR/IPV viruses: genome structure and diseases. Medicine Microbiology Immnology, v.169, p.129, 1981.

PERRIM, B., PERRIM, M., MOUSSA, A., et al. Evaluation of a commercial gE blocking ELISA test for a detection of antibodies to infectious bovine rhinotracheitis virus. Veterinary Record, v.25, n.138, p.520, 1996.

PRITCHARD, G. Diagnosing the cause of bovine abortion. In Pratice, v.12, n.3, p.92-97, 1985.

REED, R.H., MUENCH, H. A single method of estimating fifty percent end points. American Journal Hygiene, v.27, p.493$497,1938$.

ROIZMANN, B., DESROSIER, R.C., FLECKENSTEIN, B., et al. The Family Herpesviridae: an update. Archives of Virology, v.123, p.425-448, 1992

ROIZMANN, B., DESROSIER, R.C., FLECKENSTEIN, B., et al. Family Herpesviridae. Taxonomy of viruses. Archives Virology, supl.10, p.114-127, 1995.

SCHUDEL, A.A., CARILO, B.J., WYLER, R., et al. Infections of calves with antigenic variant of bovine herpesvirus 1 (BHV 1) and neurological disease. Journal Veterinary Medicine, v.33, p. 03-310,1986.

WYLER, R., ENGELS, M., SCHWYZR, M. Herpesvirus diseases of cattle, horses and pigs. London: Academic, 1990. Infectious bovine rhinotracheitis / vulvovaginites (BHV 1): p.01-07.

Ciência Rural, v. 30, n. 2, 2000. 